\title{
Assessment of accumulated personnel training as an indicator of professional development in the context of the formation of the knowledge economy
}

\author{
A.F. Stepus ${ }^{1, *}$, O.B. Glavatskikh ${ }^{2}, N . N$. Pushina $^{2}$, A.I. Troyanskaya ${ }^{2}$, and N.N. Kharitonova ${ }^{2}$ \\ ${ }^{1}$ LLC "Corporation" Axion ", st. Maxim Gorky, 90, 426000 Izhevsk, Russia \\ ${ }^{2}$ Kalashnikov Izhevsk State Technical University, Studencheskaya st., 7, 426069 Izhevsk, Russia
}

\begin{abstract}
A variant of the assessment of training and the increment of qualifications is proposed with the aim of further assigning a category for working specialties or a category for specialists and professions of a long training period. The scientific foundations of the increase in the qualifications of domestic and foreign researchers have been worked out for the development of a quantitative calculation of this increase. The practical use of this gain has also been analyzed in learning processes in its various types. This system allows the employee to influence the process of improving their qualifications. It is important that this technique will allow a self-learning organization to create a self-learning system, the personnel of which, among other things, are able to train in third-party organizations, which increases the competitiveness of both the enterprise and employees in the constantly changing modern conditions and the instability of the global economic management system.
\end{abstract}

\section{Introduction}

Recently, the processes of continuous learning and investment in education have become especially relevant, since in the context of a constantly changing market environment, it is necessary to constantly learn something new. In turn, an enterprise that implements advanced artificial intelligence technologies constantly replaces the mental analytical abilities of its specialists with the capabilities of a machine. This substitution takes place both on individual elements of personnel functions and gradually develops into individual professions as a whole. So now there is no need for a seller, there is an electronic cash register; no cashier needed - there are one-touch electronic means of payment. Developments are underway to create an artificial autopilot for transport, then a driver will not be needed. In production, automated software systems everywhere replace a person on a universal machine. As a result, even cleaners with the arrival of robotic tools are no longer needed. With the advent of distance learning and the accumulation of lecture video

\footnotetext{
* Corresponding author: stepus19811@mail.ru
} 
materials and a teacher, a robotic assistant can replace, and a general practitioner who is common in clinics - an appropriate database for the correct diagnosis, depending on the test results and symptoms. Despite the fact that this process will not take place at one moment, it will take a significant amount of time, what should an employee and employer do in such an era?

The answer to this question lies in the constant and steady improvement of qualifications, through the accumulation of an educational level in such already more complex professions of our time. In modern conditions, those enterprises survive that are able to organize within their teams a continuous process of exchange of knowledge, their transfer and development in new conditions. Those collectives of enterprises in which there is no such cooperation will at first lag behind, and later will completely leave the competitive market of goods and services. The growth of qualifications is a continuous process of development precisely in the learning processes, both from the qualitative and the quantitative side, therefore it is advisable to start developing such a methodology through the analysis of the complexity of labor by various domestic and foreign scientists. It is important that such an assessment is related to both education and the processes of its accumulation. The practical implementation of this idea will make the teams more trainable, it would be more accurate to formulate "self-learning", and as a result, more flexible to the changing market conditions in modern crisis and unstable conditions. Such employees themselves will feel more confident and value the company in which they work, precisely based on the fact that such conditions for development have been created in it.

\section{Development of a methodology for the accumulation of training and an increase in qualifications in labor units}

The essence of the increase in qualifications lies in the processes of cooperation and division of labor. The division of labor leads to the concentration of human efforts and the improvement of each such transition or operation to such a minimum duration that time is naturally saved, and, consequently, efficiency increases. The way of human cognition according to the law of universalization of people's knowledge is such that with each such improved operation or transition, the employee makes an increase in the complexity and intensity (speed) of his labor, moving the object of his further cognition to other areas, changing the application of his labor, therefore, qualifications increase. The essence of this process is reflected in the replacement of the duration of the labor process with an increase in its intensity (complexity); indeed, practice confirms that with each subsequent repetition of the same operation, a person does it faster, due to dexterity and skill. What is contained in this skill and skill, if not the ability of a person to reduce the duration by reducing transitions or eliminating unnecessary movements and actions, the ability to gradually separate and improve in a similar way already more complex operations. This pattern of human evolution was noted by Karl Marx. In his work "Critique of the Gotha Program," he wrote one of the paramount theses of the assessment of labor activity, which to a significant extent clarifies the concept of "measure of labor." Thus Karl Marx writes: "The right of producers is proportional to the labor delivered to them; equality consists in the fact that the measurement is made by an equal measure - labor ... and labor, in order for it to serve as a measure, must be defined in terms of duration or intensity, otherwise it would cease to be a measure"[1]. The union "or" contains the very process of replacing the duration of labor with its intensity or complexity. The concept of "measure of labor" was introduced into the circulation of scientific political economy by K. Marx.

The practice of implementing these aspects consisted in the dispute between various scientists who were engaged in labor reduction and intensity assessment, which continued after Karl Marx. Reduction of labor from the standpoint of the national economic 
reproduction cycle V. Pozdnyakov [2,3], P. S. Mstislavsky [4]. These views were largely shared by Academician S.G. Strumilin [5]. However, an interesting hypothesis is put forward by one of the researchers of this scientific direction - E. Varga [6], according to his opinions, all personnel, regardless of qualifications, give an equal amount of work during their life, but the time spent on training qualified personnel leads to more intensive labor, therefore, appropriate factors should be applied. So, if unskilled personnel work from 16 to 48 years - on average 32 years, then, taking into account the time spent on training (within 4 years), a qualified employee will work from 20 to 48 years - on average 28 years. From these calculations, it follows that qualified personnel (with training for 4 years) should give to society $1 / 8(=32 / 28=16 / 14=1$ whole $1 / 8)$ more work during their working life during their working life. This concept reflects the interaction and transition of one category of "duration" (number of years of work) to another category of "intensity" (characteristics of accumulated learning, time spent on learning), so the more a person learns, the more intensively he works and works with a shorter duration, as opposed to if he did not study and would work with less intensity for a longer duration. As a result, the put forward idea that personnel give an equal amount of labor during their life, taking into account the level of their quality, is confirmed by this researcher. For this reason, it is possible to equate labor costs when creating the same utility as the product of the complexity of labor and working time for different skill levels.

However, all methods of labor reduction, even within the framework of one direction, received different reduction coefficients for the same labor, the reason for which in the absence of a single measure, a unit of labor measurement, but they carried out numerous justifications for the equality of labor costs of complex and simple labor, which is the basis for derivation of the labor unit of measurement - tred. In Soviet times, treds were analyzed by S.G. Strumilin; it is this unit of measurement that it is advisable to use as a unit of accounting for accumulated training and qualifications.

After analyzing the works of domestic scientists E.A. Romanova, V. And Pavlova, A.N. Romanova [7], SG Rosental, A.I. Safina [8], O. M. Perminova, G.A. Lobanova, R.V. Faizullin, B.I. Goldfarb, E.G. Krylov, N.A. Barmina, L. Vasilevsky, G.E. Kalinkina, N.G. Sokolova, D.M. Hajikurbanov, K.V. Pavlov, V.E. Lyalin, T.A. Berkutov [9-13], as well as based on the analysis of the effectiveness of investments in education by G. Becker and professional training by J. Mintzer [14], two categories can be compared:

1. Training costs for individual "C", which consist of :

- (DC) direct costs (cost of training);

- (IC) indirect costs (lost profits if the employee did not spend time on education, but worked and received lower wages for less skilled work).

2. The present value of future benefits "P", calculated taking into account the expected increase in earnings "B" and the market rate of return on capital " $r$ " for the period in years " $t$ " by the formula:

$$
P=\Sigma \frac{B}{\llbracket 1+r \rrbracket^{t}}
$$

When comparing these categories in practice, $\mathrm{C}<\mathrm{P}$, that is, the efficiency of investment in education is high, and the rate of return on investment in education in the United States from primary education reaches $50-100 \%$, secondary $-15-20 \%$, higher $10-15 \%$, according to due to the length of the payback period and the high costs of higher education compared to the same initial.

If we consider the system of training and advanced training at large city-forming enterprises, then the costs of education for the employee himself are reduced only to lost profits, that is, $\mathrm{C}=\mathrm{IC}$, and direct costs are paid by the employer without reimbursing these 
costs, even if a trained employee is fired from the enterprise .

For the analysis, students were taken who studied during 2020 and passed to the category in 2021, since their work was paid according to the piecework payment system, their piecework earnings were analyzed, excluding incentive payments, as a result, the cost of training an individual was calculated as his loss of profit on piecework payment of his labor in a state before training.

Based on the equality of $\mathrm{P}$ and $\mathrm{C}$, as well as insignificant indirect costs that are recovered within a month of work after training, then the rate of return on capital should be considered in a month, not a year. If we consider at the microeconomic level a special case of the development of the abilities of workers, and equate the value of future benefits with the cost of training, then we get the following mathematical expression:

$$
C=P \quad, C=\Sigma \frac{B}{\llbracket 1+r \rrbracket^{t}} \text { or } B=C * \llbracket 1+r \rrbracket^{t}
$$

In turn, the selected accounting unit "tred" is disclosed by the following formula:

$$
\text { Tred }=1 \square 0,2 * \llbracket \text { Grade }-1 \rrbracket
$$

However, the work of the 1 st category is not equal to "1", we will take this value as "1.06", since simple work requires not only physical, but also mental efforts, which characterizes an increase of 0,06 . As a result, in practice, we get identical indices on average for different gains in qualifications (from 1 to 2 grade, from 2 to 3 grade ... from 4 to 5 grade) for the analyzed group of students who studied in 2020 - 2021 and passed for grade in $2021 \mathrm{r}$. As a result, such an index of growth justifies treds, as units of an increase in qualifications, in accordance with the substitution in the formula for calculating these indices and comparing the obtained values:

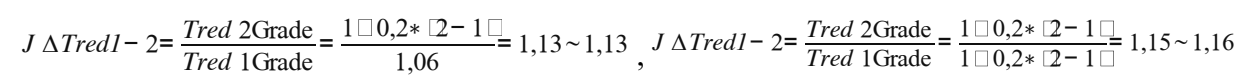

As a result, the increase in qualifications can be determined based on the accumulation of temporal characteristics of theoretical studies and subsequent certification not so much by the category, but by the treds accumulated by the employee. This aspect reveals the need to take into account the actual performance of not only workers, but also specialists.

Regarding the increase in the treds of the teaching staff, in the conditions of a selflearning organization, the incentive for teaching a teacher will be a direct cost of professional development, it is possible to calculate the change in treds, taking into account the cost of remuneration of teachers, which will determine the increase in their treds to maintain the required level qualifications.

$$
J \Delta \text { Tred }=\frac{1 \square \frac{\text { Tteaching theory }}{T \text { working basic }} \square \frac{T \text { teaching theory } * J \Delta \text { tred teaching } * J \text { teacher labor hour }}{T \text { working teacher } * N \text { number of students } \in \text { the group }} * \square+r{ }^{\star}}{J \Delta \text { labor hour } * \text { Kinimum wage }},
$$

$$
J \Delta \text { tred teaching }=\frac{\text { Tred teaching }}{\text { Tred basic }}, \quad \text { teacherlaborhour }=\frac{\text { Tteacher }}{\text { Tbase }}
$$

The index of changes in student treds will be supplemented by the ratio of the teaching time, taking into account the index of changes in the teacher's treds in comparison with the basic student treds and the index of the teacher's performance in comparison with the student's performance (in standard hours), to the product of the teacher's work time for the 
main job in the base period to the number of students in the group to whom the teacher transfers his qualifications. This formula is optimal in the case of remuneration of the teacher by the students, while this payment can be provided for under the student agreement. In the practice of some enterprises, this formula made it possible to assess the increase in qualifications in treds, depending on the type of training, as well as the status of the employee (teacher or student), while the teacher for the workers was more qualified personnel of the main workers (with the 6th grade of work), and for the specialists (bureau chiefs and leading specialists) .

\section{Analysis and application of the learning gain methodology}

According to the ratio of theoretical courses and practical classes, individual units of qualification gain were obtained, according to which, depending on the type of advanced training, status and location, the growth of treds was established directly depending on the hours of theoretical training, and a scale of tred growth was established.

Table 1. Scale for assessing the accumulation of labor complexity in the course of training

\begin{tabular}{|c|c|c|c|c|}
\hline $\begin{array}{c}\text { Type of } \\
\text { employee } \\
\text { qualification } \\
\text { improvement }\end{array}$ & $\begin{array}{c}\text { Type of } \\
\text { participatio } \\
\text { n (status) }\end{array}$ & Location & $\begin{array}{l}\text { Increase in the } \\
\text { complexity of } \\
\text { labor in treds per } \\
1 \text { unit of measure. }\end{array}$ & $\begin{array}{c}\text { Unit of } \\
\text { measurement }\end{array}$ \\
\hline \multirow{4}{*}{ Report } & \multirow{2}{*}{ Teacher } & In company & 0,0068 & Hour \\
\hline & & Outside the company & 0,0102 & Hour \\
\hline & \multirow{2}{*}{ Pupil } & In company & 0,0020 & Hour \\
\hline & & Outside the company & 0,0034 & Hour \\
\hline \multirow{4}{*}{ Lecture } & \multirow{2}{*}{ Teacher } & In company & 0,0082 & Hour \\
\hline & & Outside the company & 0,0122 & Hour \\
\hline & \multirow{2}{*}{ Pupil } & In company & 0,0020 & Hour \\
\hline & & Outside the company & 0,0034 & Hour \\
\hline \multirow{4}{*}{ Presentation } & \multirow{2}{*}{ Teacher } & In company & 0,0204 & Hour \\
\hline & & Outside the company & 0,0340 & Hour \\
\hline & \multirow{2}{*}{ Pupil } & In company & 0,0020 & Hour \\
\hline & & Outside the company & 0,0034 & Hour \\
\hline \multirow{4}{*}{ Training } & \multirow{2}{*}{ Teacher } & In company & 0,0204 & Hour \\
\hline & & Outside the company & 0,0306 & Hour \\
\hline & \multirow{2}{*}{ Pupil } & In company & 0,0068 & Hour \\
\hline & & Outside the company & 0,0136 & Hour \\
\hline \multirow{5}{*}{ Test } & \multirow{2}{*}{ Teacher } & In company & 0,0068 & Day \\
\hline & & Outside the company & 0,0136 & Day \\
\hline & \multirow{3}{*}{ Pupil } & In company & 0,0136 & $\begin{array}{c}\text { For satisfactory } \\
\text { delivery }\end{array}$ \\
\hline & & & 0,0204 & \\
\hline & & Outside the company & & $\begin{array}{c}\text { For satisfactory } \\
\text { delivery }\end{array}$ \\
\hline \multirow{4}{*}{$\begin{array}{l}\text { Seminar, } \\
\text { exhibition }\end{array}$} & \multirow{2}{*}{ Teacher } & In company & 0,0272 & Day \\
\hline & & Outside the company & 0,0408 & Day \\
\hline & \multirow[b]{2}{*}{ Pupil } & In company & 0,0136 & Day \\
\hline & & Outside the company & 0,0204 & $\begin{array}{c}\text { Day without } \\
\text { road }\end{array}$ \\
\hline
\end{tabular}


Table 1. Continued

\begin{tabular}{|c|c|c|c|c|}
\hline \multirow{4}{*}{ Exam } & \multirow{2}{*}{ Teacher } & In company & 0,0068 & Day \\
\cline { 3 - 5 } & \multirow{3}{*}{ Pupil } & Outside the company & 0,0136 & Day \\
\cline { 3 - 5 } & & In company & 0,0136 & $\begin{array}{c}\text { For satisfactory } \\
\text { delivery }\end{array}$ \\
\cline { 3 - 5 } & Outside the company & 0,0204 & $\begin{array}{c}\text { For satisfactory } \\
\text { delivery }\end{array}$ \\
\hline $\begin{array}{c}\text { Self- } \\
\text { preparation }\end{array}$ & Pupil & In company & 0,0136 & $\begin{array}{c}100 \text { pages } \\
\text { information }\end{array}$ \\
\hline \multirow{2}{*}{ Certificate } & \multirow{2}{*}{ Pupil } & In company & 0,0408 & 1 piece \\
\cline { 3 - 5 } & $\begin{array}{c}\text { Personal outside the } \\
\text { company }\end{array}$ & 0,0272 & 1 piece \\
\hline
\end{tabular}

In addition to the number of hours, it is necessary to take into account their quality level for each course read, and it is also necessary to keep an electronic record of advanced training according to the formulas:

$$
\text { Tred }=\sum \Delta \text { Tred } * \text { Tteach } * \text { Score } \llbracket 1-\text { offset }, 0-\text { notoffset } \rrbracket, \text { Tred }=\sum \Delta \text { Tred } * \text { Tteach } * \frac{\text { Score }(1-5)}{4}
$$

According to the accumulated treds, it is possible to assign an individual qualification level in the certification process, the category of personnel complexity changes and the level of payment increases. After attestation, the accumulated treds in the Personal Competitiveness Card of the Personnel under the "Professional Development" section are canceled, and over the next five years the employee must accumulate the desired value of treds or increase it by raising qualifications in the status of a student or teacher.

Table 2. Scale of requirements for accumulated training for personnel workplaces

\begin{tabular}{|c|c|c|}
\hline Category & Grade & Treds \\
\hline \multirow{3}{*}{ Working } & 1 & 1,06 \\
\cline { 2 - 3 } & 2 & 1,2 \\
\cline { 2 - 3 } & 3 & 1,4 \\
\cline { 2 - 3 } & 4 & 1,6 \\
\cline { 2 - 3 } & 5 & 1,8 \\
\cline { 2 - 3 } & 6 & 2,01 \\
\hline \multirow{2}{*}{ Technician by profession } & 7 & 2,4 \\
\hline Senior technician by profession & 8 & 2,6 \\
\hline Specialist without category & 9 & 2,9 \\
\hline Specialist of the 3rd category & 10 & 3,2 \\
\hline Specialist of the 2rd category & 11 & 3,6 \\
\hline Specialist of the 1rd category & 12 & 3,9 \\
\hline Leading Specialist & 13 & 4,8 \\
\hline
\end{tabular}

Using the method of expert assessments, the conclusion was substantiated that this method can prove itself on a positive side in the management practice of advanced training and training at any enterprises that seek to create a self-learning organization in their environment. 


\section{Conclusions}

The conducted research allows us to draw some general conclusions:

1. Sustainable development of any organization as an economic system implies constant training of personnel, which requires quantitative accounting, which is both more objective and more reasonable.

2. This technique is more effective if its results are used at the stage of personnel certification, this would motivate to maintain the level of qualifications both through training as a student and the transfer of knowledge as a teacher, this allows solving one of the most difficult problems - the voluntary transfer of knowledge from more experienced employees to less experienced.

3. It is advisable in the prospect of applying such a method to introduce incentive payments for the difference in excess of the accumulated training of your qualification level, such an additional payment could be called "a personal bonus for professional level / professional skill" - this would also motivate to return knowledge and skills and to participate in training.

As a result of the study, a methodology was developed for taking into account the increase in qualifications in the learning processes. The obtained data were drawn up as recommendations for the advanced training service in the framework of the direction of personnel management of the enterprise.

\section{References}

1. Karl Marx, Criticism of the Gotha Program (1977)

2. V.N. Pozdnyakov, Bulletin of the Communist Academy (1925)

3. V.N. Pozdnyakov, Skilled Labor and Marx's Theory of Value (1924)

4. P.S. Mstislavsky, Abstracts of the report at the union conference on the reduction oflabor. (1969)

5. S.G. Strumilin, Selected works in 5 volumes, 3 volumes. (1964)

6. E.S. Varga, Economics of Life, 259 (1920)

7. E.A. Romanov, V.I. Pavlova, A.N. Romanova, Vestnik SURGU, 37 (2010)

8. S.G. Rosenthal, A.I. Safina Scientific Notes of Kazan University, Series Natural Sciences, 157(3) (2015)

9. V. I. Goldfarb, E. G. Krylov, O. M. Perminova, N. A. Barmina, L. Vasiliev, Aspects of Teaching Future Mechanical Engineers on Bachelor of Science Programs at Technical Universities (2018)

10. K.V. Pavlov, O.M. Perminova, V.E. Lyalin, G.E. Kalinkina, T.A. Berkutova, 24th International Vibration Engineering Conference (2016)

11. O.M. Perminova, G.A. Lobanova, Acta Logistica, 1(5) (2018)

12. O. M. Perminova, G.A. Lobanova, R.V. Faizullin, Acta Logistica, 2 (2019)

13. G.E. Kalinkina, N.G. Sokolova, D.M. Hajikurbanov, O.M. Perminova, "23rd International Conference on Vibration Engineering" (2016)

14. G. S. Becker, The Economic Approach to Human Behavior (1976) 